\title{
Global distribution of magnetic ripples and electron density fluctuations as observed by the Swarm satellites on the dayside and their relation to the rainfall estimated by the GSMaP
}

\author{
Toshihiko lyemori $^{*} \mathbb{D}$, Tadashi Aoyama² and Yoshihiro Yokoyama ${ }^{3}$
}

\begin{abstract}
In mid- and low-latitude ionospheric F-region on the dayside, magnetic field and electron density (Ne) fluctuations with amplitude smaller than a few $n T$ and 1-2\% of Ne, respectively, are commonly observed. Their spatial scale along satellite orbit is around $70-250 \mathrm{~km}$. It is presumed that they are generated by the waves propagated from lower atmosphere. However, the mode of waves (acoustic wave or internal gravity wave) and their source are not yet clear. Among the possible sources, cumulus convection and/or associated rainfall are considered to be the strong candidates for the atmospheric wave generation. We use the rainfall estimated by the hourly Global Satellite Mapping of Precipitation (JAXA/GSMaP) as a proxy of lower atmospheric disturbance as the wave source, and compare the rainfall with the amplitude of magnetic fluctuations (magnetic ripples) and electron density fluctuations observed by the Swarm satellites. The data from April 2014 to July 2020 are used. The global distribution of rainfall estimated by the GSMaP and its seasonal variation have similarities with amplitude distribution of magnetic ripples and electron density fluctuations on the dayside. We calculate the ratio of their magnitude, i.e., amplitude of magnetic ripples or electron density fluctuations in rainfall cases to those in no-rainfall cases. Although the longitudinally averaged ratio is not very large but around 1.1-1.2 in $\pm 10- \pm 50^{\circ}$ Apex latitudes, it is clearly larger than 1.0. The ratio increases when the intensity of rainfall $(\mathrm{mm} / \mathrm{h})$ increases. These results indicate that a cumulous convection which causes rainfall is one of the main sources of atmospheric waves that produce magnetic ripples and electron density fluctuations commonly observed in the dayside ionosphere. Anticipating acoustic waves as the driver of magnetic ripples and electron density variations, a difference in the generation mechanism of electron density fluctuations from that of magnetic ripples is suggested even if their sources are common.
\end{abstract}

Keywords: Magnetic ripples, Electron density fluctuations, Rainfall, Swarm satellites, Atmospheric waves, GSMaP, Dayside ionosphere, Vertical coupling

\footnotetext{
*Correspondence: iyemori.toshihiko.7w@kyoto-u.jp

${ }^{1}$ Graduate School of Science, Kyoto University, Kyoto 606-8502, Japan

Full list of author information is available at the end of the article
}

(c) The Author(s) 2022. Open Access This article is licensed under a Creative Commons Attribution 40 International License, which permits use, sharing, adaptation, distribution and reproduction in any medium or format, as long as you give appropriate credit to the original author(s) and the source, provide a link to the Creative Commons licence, and indicate if changes were made. The images or other third party material in this article are included in the article's Creative Commons licence, unless indicated otherwise in a credit line to the material. If material is not included in the article's Creative Commons licence and your intended use is not permitted by statutory regulation or exceeds the permitted use, you will need to obtain permission directly from the copyright holder. To view a copy of this licence, visit http://creativecommons.org/licenses/by/4.0/. 


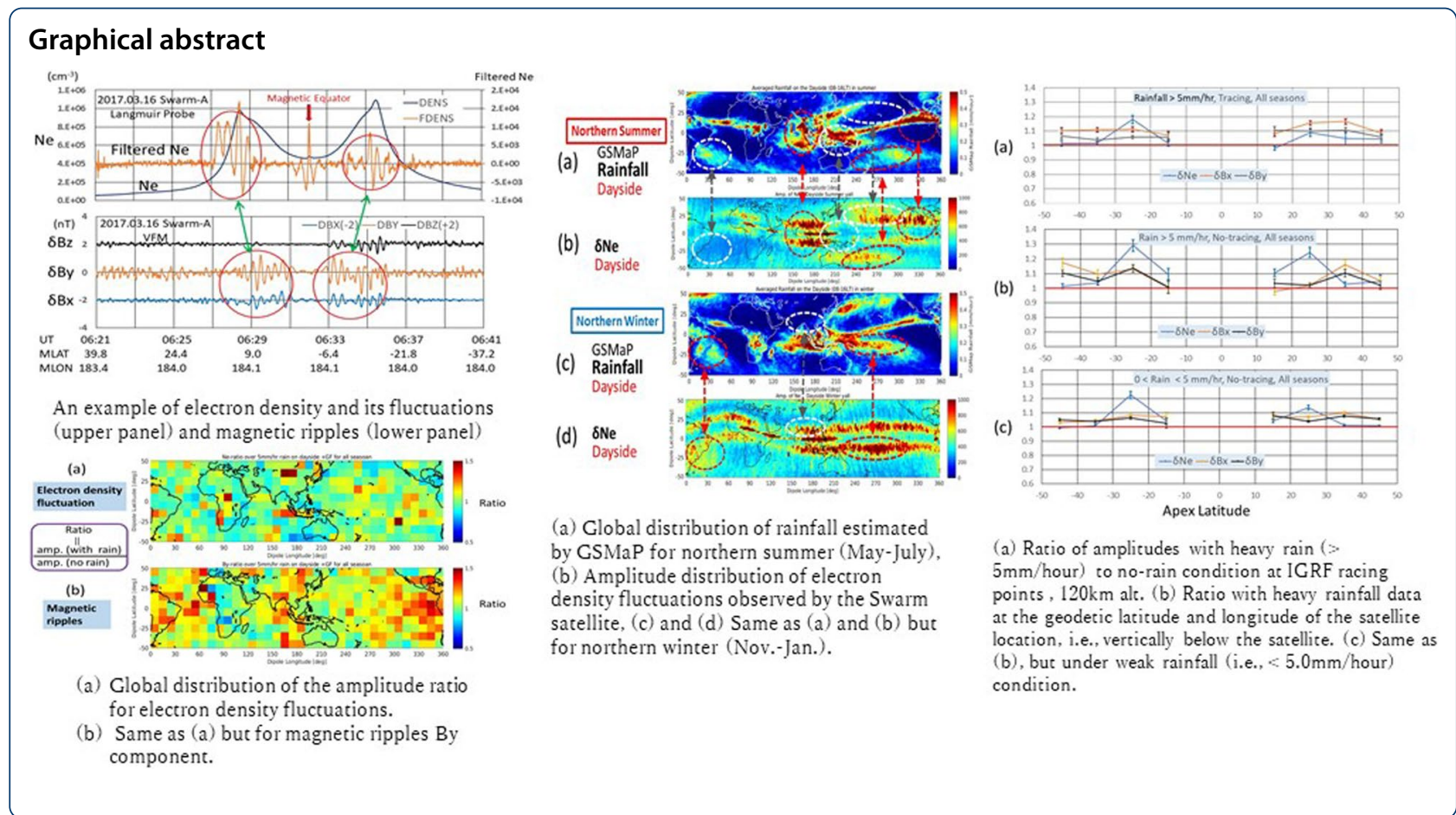

\section{Introduction}

By applying a high-pass filter to the vector magnetic field data obtained by the CHAMP satellite to subtract the geomagnetic main field including large scale crustal anomaly, Nakanishi et al. (2014) found a small amplitude (less than a few nT) and short period (10-30 s) wavy variations along the satellite orbit. Iyemori et al. (2015) concluded that they are small spatial scale field-aligned currents probably generated in the lower ionosphere by acoustic mode atmospheric waves by using the Swarm satellite observation when the three satellites were flying almost on the same orbits in the initial period after their launch. The characteristics of the small-scale magnetic variations observed by the Swarm satellites are exactly the same with those observed by the CHAMP satellite (Aoyama et al. 2016). Aoyama et al. $(2016,2017)$ analyzed the correlation of the small-scale magnetic variations with a volcanic eruption, typhoons and cloud-top temperature. They named the magnetic variation as "magnetic ripples" anticipating that the magnetic structure expands as the atmospheric waves in the lower ionosphere, which generate the field-aligned currents, expand. A numerical simulation by Zettergren and Snively $(2015,2019)$ supports the formation of field-aligned currents by acoustic waves.

By applying the same filtering method for magnetic ripples to the electron density data obtained by the Swarm satellites, similar to the magnetic ripples but slightly different wavy structure is commonly observed on the dayside, which shall be introduced in this paper. That is, the location and period along the satellite orbit are, in general, not the same with those of magnetic ripples, which suggests different generation mechanism. However, the characteristics similar to those of magnetic ripples also exist, and they could have a common source in lower atmosphere.

It has been reported that the lower atmospheric waves, in particular, acoustic mode waves generated by strong earthquakes, volcanic eruptions, typhoons and tornadoes propagate to the ionosphere and causes geomagnetic variations and ionospheric electron density variations. For example, geomagnetic oscillations with a period of vertical acoustic resonance at $3.7 \mathrm{mHz}$ were observed in Thailand during the 2004 Sumatra earthquake (Iyemori et al. 2005; Shinagawa et al. 2007). Similar oscillation was also observed in GPS-TEC data (Choosakul et al. 2009).

Generation of atmospheric waves, in particular the acoustic waves, have been reported by using seismometers, micro-barometers, ionosondes, GPS-array, etc. before this Sumatra event (e.g., Calais and Minster 1995; Kanamori et al. 1994 and references therein). After the Sumatra event, we have many reports of ionospheric effects by the special events such as earthquakes (e.g., Heki and Ping 2005; Saito et al. 2011), volcanic eruptions (e.g., Heki 2006; Aoyama et al. 2016), typhoons (e.g., Perwitasari et al. 2015; Aoyama et al. 2017; MartinesBedenko 2019) and tornadoes (e.g., Nishioka et al. 2013) by using the new tools such as global and dense network of GPS-TEC observations, precise satellite observations 
of electro-magnetic fields and plasmas, all-sky imagers, satellite imagers etc.

However, the magnetic ripples are commonly observed on the dayside by polar orbiting satellite with precise magnetic measurement such as the CHAMP and the Swarm satellites. If magnetic ripples are also caused by lower atmospheric waves, the source should not be the special events such as earthquakes, volcanic eruptions or typhoons but should be some commonly existing phenomena. One of the candidates is enhanced cumulous convection, and Aoyama et al. (2017) showed a correlation of global amplitude distribution of magnetic ripples observed by the Swarm satellites and cloud top temperature estimated by meteorological satellites as a proxy of cumulous convection activity. Shao and Lay (2016) presented some examples of correlation between GPS-TEC oscillation with period about $3-5 \mathrm{~min}$ and thunderstorms that are more common than the above special events.

In this paper, we use global rainfall estimation provided by the JAXA/GSMaP as a proxy of lower atmospheric disturbance which generate atmospheric waves, in particular, acoustic mode waves which can propagate vertically upward. The advantage of using rainfall data by GSMaP is their global coverage and high spatial and temporal resolution. As the first step, we compare the global amplitude distribution of magnetic ripples and electron density fluctuations to that of rainfall. Then we examine the ratio of amplitude in the cases when rainfall is observed below the satellite location to that in the cases when no-rainfall is observed.

\section{Data and method of analysis}

\section{Magnetic ripples and electron density fluctuations}

The vector magnetic field data and the electron density data obtained by the three Swarm satellites (Olsen et al. 2013) are used to detect magnetic ripples and electron density fluctuations in middle and low latitude ionosphere. The Swarm constellation consists of three satellites (SW-A, -B and -C) placed in two different polar orbits, i.e., SW-A and -C fly side by side (with about 1.4 degrees separation in longitude) at gradually decreasing altitude around $480-450 \mathrm{~km}$, while SW-B has been at around $530-515 \mathrm{~km}$ during the period of data used in this analysis, i.e., from April 2014 to July 2020.

We use one second resolution vector magnetic field data obtained by the VFM (e.g., Merayo 2014), in the sensor coordinate system $(x, y, z)$, where $x$ approximately points upward or downward, $y$ points longitudinal direction and $z$ approximately points satellite velocity direction, and $0.5 \mathrm{~s}$ resolution electron density data (Advanced/2 Hz Langmuir Probe Extended Dataset) obtained by the Langmuir probe (Knudsen et al. 2017). Because the temporal resolution of the VFM data used in this analysis is $1 \mathrm{~s}$, we averaged two values of electron density $(\mathrm{Ne})$ data within each one second to make $1 \mathrm{~s}$ resolution dataset to merge with the VFM dataset for convenience of analysis.

To extract the small amplitude fluctuations, i.e., less than a few nT or less than a few $\%$ of $\mathrm{Ne}$, with period about 10-40 s from rapidly varying large values of the geomagnetic main field or electron density along satellite orbit, we subtract the base values by applying 2 nd order B-Spline fitting with a knot interval of $20 \mathrm{~s}$. This filter is the same as that used in Nakanishi et al. (2014). Because there still remain small-scale variation probably of crustal origin in $\mathrm{Bx}$ and $\mathrm{Bz}$ components even after the Spline filtering, we further applied a Gaussian type high-pass filter with a standard deviation $\sigma=8 \mathrm{~s}$ to the Spline filtered data. The same procedure was used also for electron density variations.

In this paper, we show only the results obtained on the dayside (i.e., 08-16MLT; Magnetic Local Time) because the amplitude of magnetic ripples is strongly controlled by the ionospheric conductivities (Nakanishi et al. 2014; Aoyama et al. 2017), and the density variations on the dayside which we shall show in this paper seems to be different from "plasma bubble" with large amplitude density variation caused by the Rayleigh-Taylor instability (e.g., Stolle et al. 2006; Park et al. 2009). They are also different from the "MEF" (Mid-latitude Electric field Fluctuation) and the "MMF" (Mid-latitude Magnetic field Fluctuation) possibly caused by the Perkins instability (e.g., Perkins 1973; Saito et al. 1995; Park et al. 2016) which mostly appears on the nightside.

In the analysis of electron density data, we realized that, during a considerable period of observation, the electron density data are contaminated by apparently non-natural phenomena. They typically start to appear at nearly the same geodetic latitude during the day with small amplitude and small latitudinal width and expand to other latitudes with enhanced amplitude and wide latitudinal width (see Fig. 12). They appear, for example, in the data of both the Swarm A and C with a time delay of a few days with very similar shape. They last for a few days or for a few weeks and appear in most of local time except for around noon, midnight, dawn and sunset, and about $1 / 3$ of the period is contaminated with such variation. We plot all of the data from March 2014 to July 2020 in the same format with Fig. 12 and searched the period contaminated with such variations by eye-inspection (see Fig. 13). Because both the Swarm A and C flying with a small longitudinal difference of about 1.4 degree show very similar variation with a few days delay, we speculate that the phenomena could be related to the satellite attitude relative to the Sun. In the analysis, such periods were excluded. 


\section{Global rainfall estimation}

To examine the effect of lower atmospheric waves on the generation of magnetic ripples or electron density fluctuations on the dayside, we need some appropriate meteorological parameters to compare with satellite observation. As a proxy of lower atmospheric disturbances which may produce atmospheric waves, we use the global distribution of hourly rainfall estimated by JAXA/GSMaP (https://sharaku.eorc.jaxa.jp/GSMaP/ index.htm). GSMaP uses Dual-frequency Precipitation Radar (DPR) onboard Global Precipitation Measurement (GPM) core satellites, other GPM constellation satellites, and Geostationary satellites (https://sharaku.eorc.jaxa.jp/ GSMaP/guide.html). The hourly rainfall data are used in this paper and they are available since March 2014 with a spatial resolution of $0.1^{\circ} \times 0.1^{\circ}$ in geodetic latitude and longitude. In the analysis, considering the temporal resolution of the GSMaP (i.e., $1 \mathrm{~h}$ ) and altitude difference between ground and the ionosphere, we averaged them in $1.0^{\circ} \times 1.0^{\circ}$ mesh and compared with the Swarm satellite data.

\section{Global distribution of rainfall, electron density variations and magnetic ripples}

The Swarm and the GSMaP data are converted to a dipole coordinate system and averaged in $2^{\circ} \times 2^{\circ}$ mesh to obtain the average global distribution of rainfall, amplitude (magnitude) of electron density fluctuations and magnetic ripples defined as the absolute value of $\delta \mathrm{Ne}$ and $\delta \mathrm{Bx}$ (or $\delta \mathrm{By}$ or $\delta \mathrm{Bz}$ ). We limit our analysis within \pm 50 degrees in dipole latitude. The data period analyzed in this paper is from 17 April 2014 to 29 July 2020.

\section{Difference of amplitude between the cases of rainfall and no-rainfall}

To see the rainfall effect on the amplitude of magnetic ripples and electron density fluctuations, the amplitude ratio of the cases with rainfall to the cases with no-rainfall is calculated for each $10^{\circ} \times 10^{\circ}$ mesh in dipole coordinates (Fig. 6) and in Apex coordinates (Fig. 8). The Apex latitude (VanZandt 1972; Richmond 1995) at a given point is defined as the dipole latitude of the dipole magnetic lines of force which pass the apex, i.e., most distant point from the center of the Earth, where the realistic geomagnetic field, i.e., IGRF model field in this case, is traced from a given point along the magnetic lines of force as schematically depicted in Fig. 1. If the distance between an apex and the center of the Earth is La in unit of the Earth radius, the apex latitude $\alpha$ is defined as $\alpha=\cos ^{-1}(\sqrt{ }(1 / L a))$. It should be noted that the Apex latitude depends on the altitude of a given point even if the geodetic or dipole latitude is the same. Therefore,

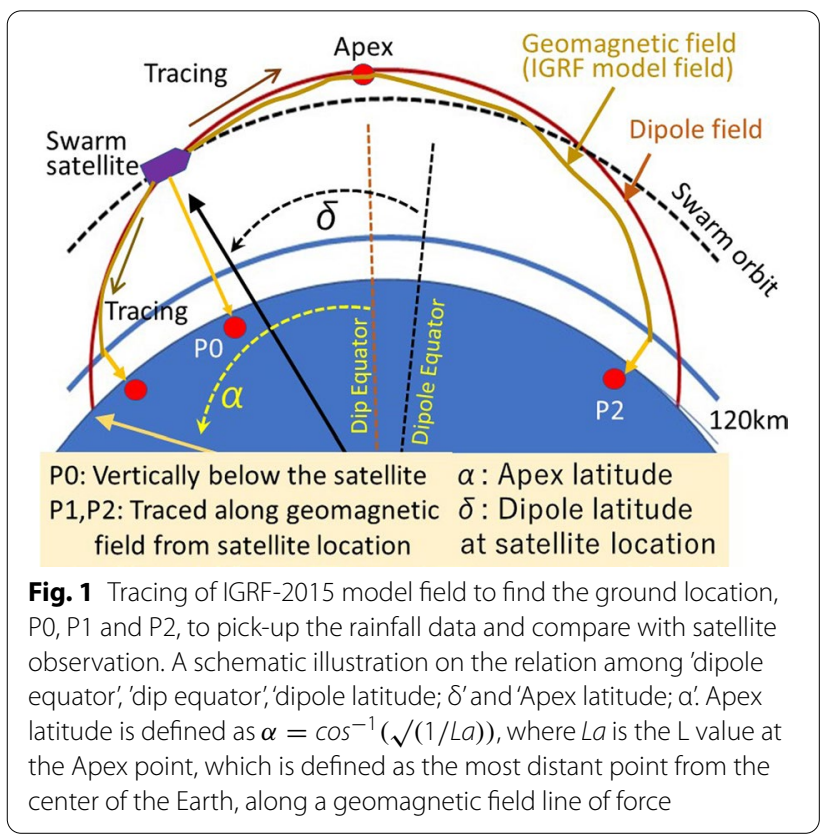

there appears a jump in Apex latitude of satellite along the orbit in low latitude where the geomagnetic lines of force do not reach the satellite altitude.

The amplitude of magnetic ripples (or electron density fluctuations) is averaged in each mesh for the cases when we have rainfall and no-rainfall, and then we take a ratio of averaged amplitude in rainfall cases to that in no-rainfall cases. We averaged the ratios of the meshes in the same Apex latitude to get longitudinal average shown in Figs. 9, 10 and 11. Details on these figures shall be explained later in "Results and discussion" section.

Figure 1 illustrates the method to compare the Swarm satellite observation and rainfall estimated by the GSMaP as well as the difference between a dipole latitude and an Apex latitude. To find the location where the GSMaP data are picked up, a model geomagnetic fields, IGRF2015 (coefficients at epoch 2015.0 of IGRF-12 model, see http://www.ngdc.noaa.gov/IAGA/vmod/igrf.html), are traced from the satellite location to a geodetic altitude $120 \mathrm{~km}$ in both hemispheres, P1 and P2 in Fig. 1. The reason of tracing to an altitude $120 \mathrm{~km}$ in both hemispheres is that the magnetic ripples are assumed to be generated by E-region dynamo driven by the atmospheric waves, and divergence of the dynamo current forms the fieldaligned currents. That is, the source could be in opposite hemisphere to the hemisphere where a satellite is observing the fluctuations.

Then, we take the strength of rainfall $(\mathrm{mm} / \mathrm{h})$ at the geodetic latitude and longitude of P1 and P2 in Fig. 1 from corresponding hourly GSMaP dataset. We also used the rainfall data at P0, vertically below the satellite 
for comparison. Considering the horizontal expansion of waves when they propagate upward from troposphere to $120 \mathrm{~km}$ altitude, we take the maximum value of rainfall in longitudinal width of \pm 1 degree. On the latitude, we use the latitudes at P1, P2 and P0 without taking any latitudinal width because the satellite moves rapidly in latitudinal direction and covers 1 degree within about $14 \mathrm{~s}$.

\section{Results and discussion}

Figure 2 shows an example of electron density, $\mathrm{Ne}$ (blue line), and its fluctuations, $\delta \mathrm{Ne}$ (orange line), (upper panel, both in $\mathrm{cm}^{-3}$ ) and magnetic ripples (lower panel, in $\mathrm{nT}$ ) in low-latitudes on the dayside observed by the Swarm-A on 16 March 2017. The equatorial fountain effect is clearly seen and the electron density fluctuations are observed on both sides of equatorial electron density anomaly. The latitude of a sharp Ne fluctuation peak around 06:32:30UT corresponds to the geomagnetic dip-equator, and a sharp peak and two depressions and small peaks on both sides are probably a high-pass filtering effect of a peak or a step-wise variation of $\mathrm{Ne}$ at the dip equator. This type of fluctuations at the dip-equator is often observed when the fountain effect is strong. It should be noted that the location of electron density fluctuations and that of magnetic ripples are slightly shifted, i.e., different in latitude. This shift suggests that the mechanism of electron density fluctuations is different from that of magnetic ripples even if the sources in lower atmosphere could be the same. We shall discuss on this latitudinal shift later with Fig. 11.

Figure 3 shows the global distribution of electron density fluctuations (in $\mathrm{cm}^{-3}$ ) and magnetic ripples of Bycomponent (in nT) for the four seasons on the dayside. The one second resolution data are averaged in $2^{\circ} \times 2^{\circ}$ mesh in a dipole coordinate system. Clear seasonal differences are observed. On the electron density fluctuations shown in the left panels, in general, their amplitude is large in the region where the electron density is large by the equatorial fountain effect. We see a narrow peak along geomagnetic equator where the plasma flow is expected to be upward by the eastward electric field. The global distribution of $\delta \mathrm{Ne}$ is similar between vernal equinox (Feb-Apr) and autumnal equinox (Aug-Oct). However, we see some clear difference in the cases of June solstice (May-July) and December solstice (Nov-Jan). That is, we see amplitude enhancement of $\delta \mathrm{Ne}$ in northern and southern Pacific Ocean, a hemispheric asymmetry in Eastern Pacific Ocean in June solstice, and an enhancement in the southern part of South America and Atlantic Ocean in December solstice. In the equatorial enhancement latitudes, the amplitude is larger around

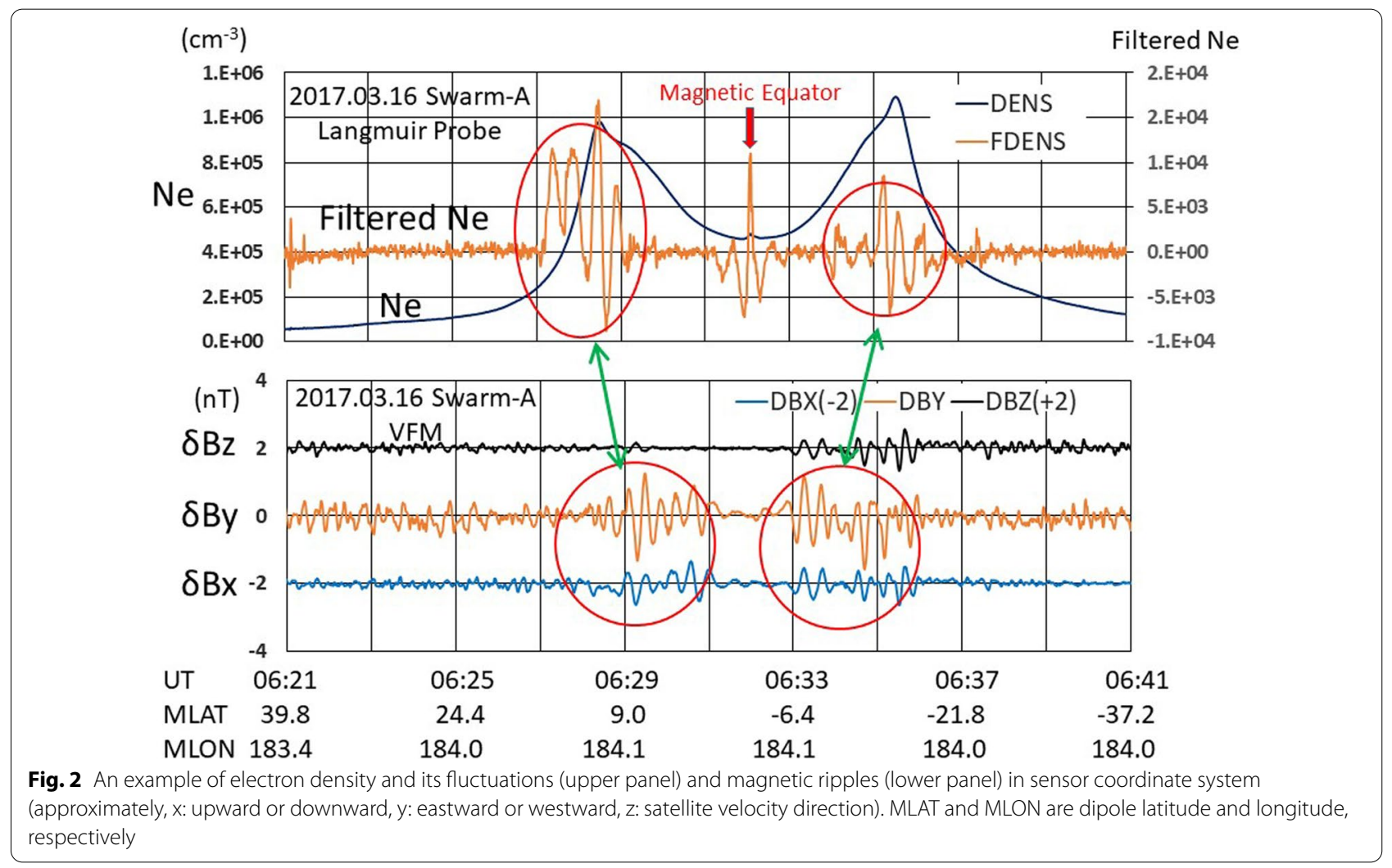




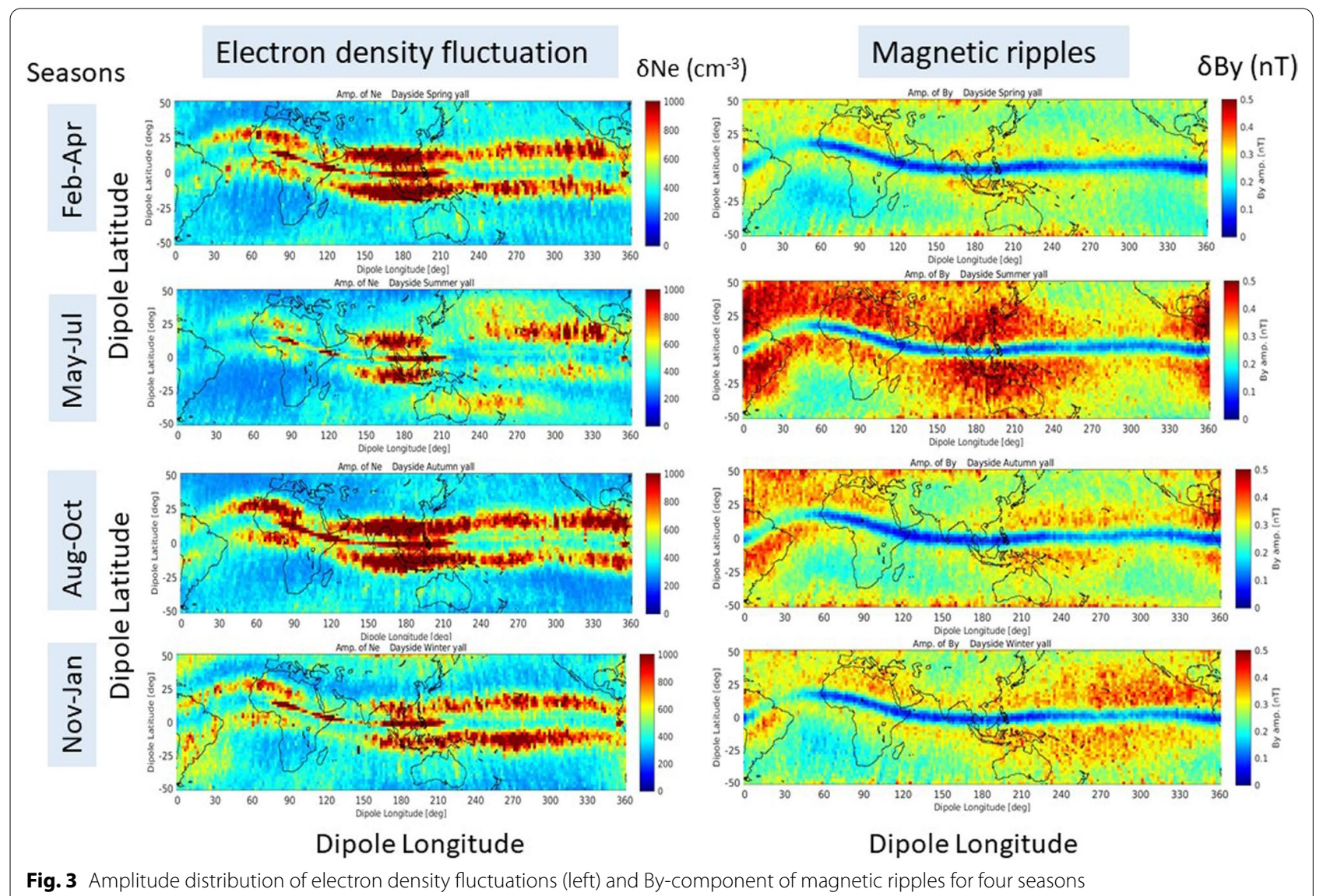

South-East Asia in June solstice and South Pacific Ocean in December solstice.

The right panels of Fig. 3 show the amplitude distribution of magnetic ripples. In general, we see geomagnetic conjugacy and they show a very clear seasonal difference. In June solstice, the amplitude is larger than other seasons in most area. In particular, the amplitude in South-East Asian and American longitudes is large. In December solstice, the amplitude in Eastern Pacific Ocean is larger than that in other areas. The depression of the amplitude of magnetic ripples along magnetic equator depicted in deep blue or blue is caused by the satellite velocity direction which is nearly parallel to geomagnetic field around the dip-equator, and hence, parallel to the small-scale field-aligned currents that cause magnetic ripples. That is, the satellite cannot detect magnetic variation caused by the field-aligned currents when it flies along geomagnetic field near the dip-equator, because the apparent wave length becomes too long and filtered-out by the high-pass filter to remove Earth's main field (see Fig. 3 and Fig. 13 in Nakanishi et al. 2014). The difference in the global distributions and their seasonal variation between electron density fluctuations and magnetic ripples suggest a difference in the mechanism to cause the electron density variation and magnetic ripples.

Figure $4 \mathrm{a}$ and $\mathrm{b}$ respectively show the averaged distribution of global rainfall $(\mathrm{mm} / \mathrm{h})$ and electron density fluctuations $\left(\mathrm{cm}^{-3}\right)$ in June solstice (May-July), and Fig. $4 \mathrm{c}$ and d respectively show those in December solstice (Nov-Jan). Note that these plots are also presented in a dipole coordinate system. In June solstice, we have a strong rainfall in the South Eastern Asia and Pacific Ocean side of Central America. In December solstice, large amount of rainfall is observed in the South Pacific Ocean and South America and its Atlantic Ocean side. Corresponding to these areas, we observe larger amplitude of electron density fluctuations than another season as indicated by red dashed-line circles and arrows. However, there exist the regions where no good correspondence is seen as shown by white dashed-line circles and dark gray arrows. This could mean that a rainfall is not enough as a proxy of the wave source but there exist other sources that a rainfall cannot be the proxy of wave source. The ambient electron density and/or vertical 


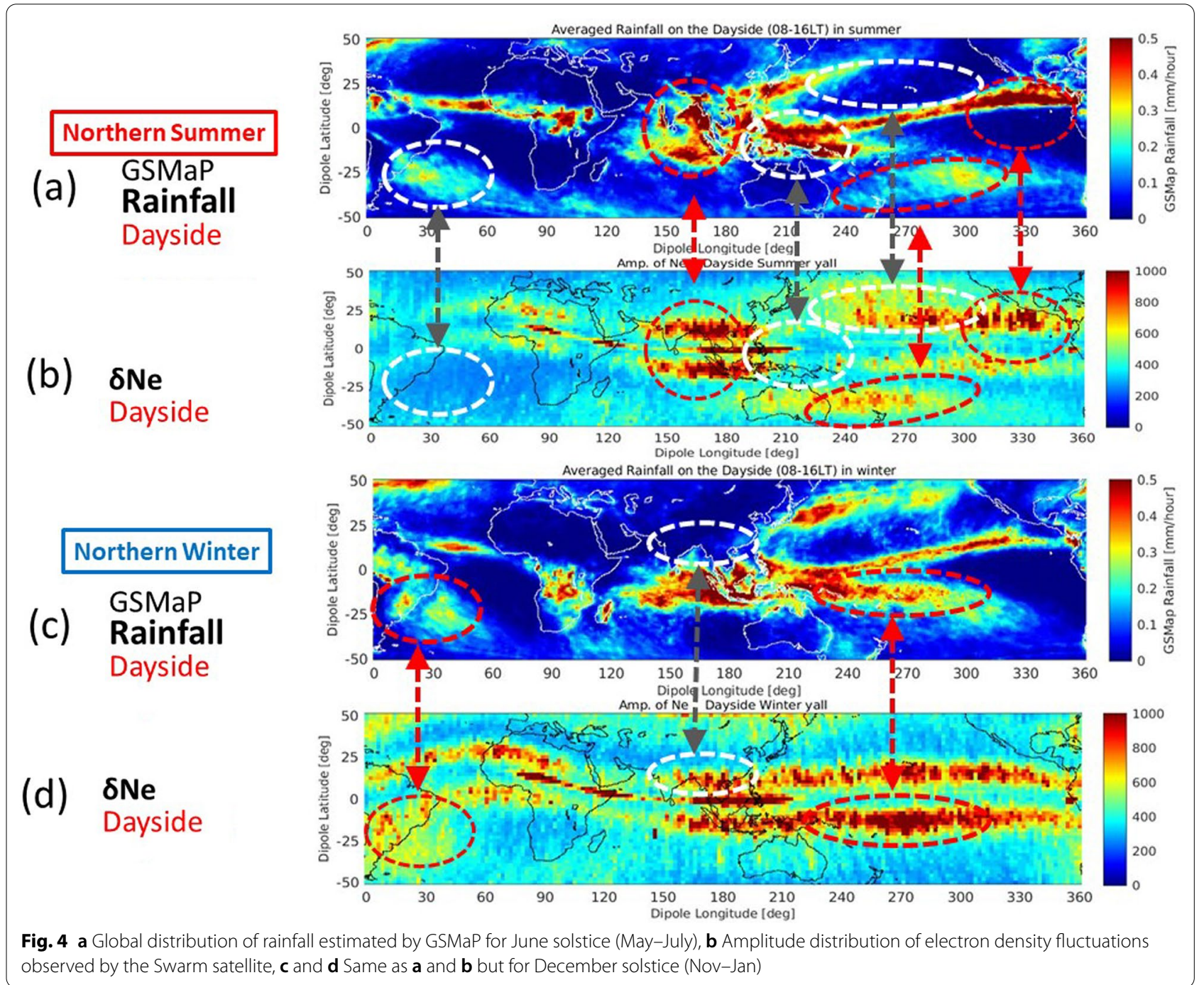

electron density gradient at satellite altitudes may also need to be large enough to have appreciable amplitude of $\delta \mathrm{Ne}$.

Figure $5 \mathrm{a}$ and $\mathrm{b}$ are respectively the difference of average rainfall and amplitude of electron density fluctuations between autumnal equinox and vernal equinox. By taking the difference, we expect that the large equatorial fountain effect in electron density variations is cancelled out or reduced to some extent. We see a better correspondence between the rainfall and $\delta \mathrm{Ne}$, because the ionospheric condition controlled by solar radiation is expected to be similar for the two equinoxes although the meteorological condition is rather different.

Figure 6a shows the ratio between averaged amplitude of electron density fluctuations in $10^{\circ} \times 10^{\circ}$ mesh when the rainfall stronger than $5 \mathrm{~mm} / \mathrm{h}$ is observed at one or both sides of magnetic conjugate points and when no rainfall was observed in both hemispheres, i.e., at P1 and P2 in Fig. 1. Figure 6b shows the ratio between averaged amplitude of magnetic ripples in the same condition with that of Fig. 6a. In many of the mesh areas, the color is yellow or orange, in particular, in Fig. 6b. That is, the ratio is greater than 1.0 in many areas. This indicates the contribution of rainfall, or that of the meteorological condition which causes rainfall, to the amplitude of $\delta \mathrm{Ne}$ and $\delta \mathrm{By}$. The results for $\delta \mathrm{Bx}$ are also similar to those for $\delta \mathrm{By}$ (not shown here). The results for $\delta \mathrm{Bz}$, i.e., component approximately in satellite velocity direction near the magnetic equator, is not shown because the amplitude of z-component nearly parallel to the geomagnetic field in low-latitudes is very small as seen in Fig. 2.

Figure $7 \mathrm{a}, \mathrm{b}$ and $\mathrm{c}$ shows the number of the data points in a $10^{\circ} \times 10^{\circ}$ mesh used to obtain the results shown in Fig. $6 a$ and b. Figure $7 \mathrm{a}$ shows the case with no-rainfall, $b$ 


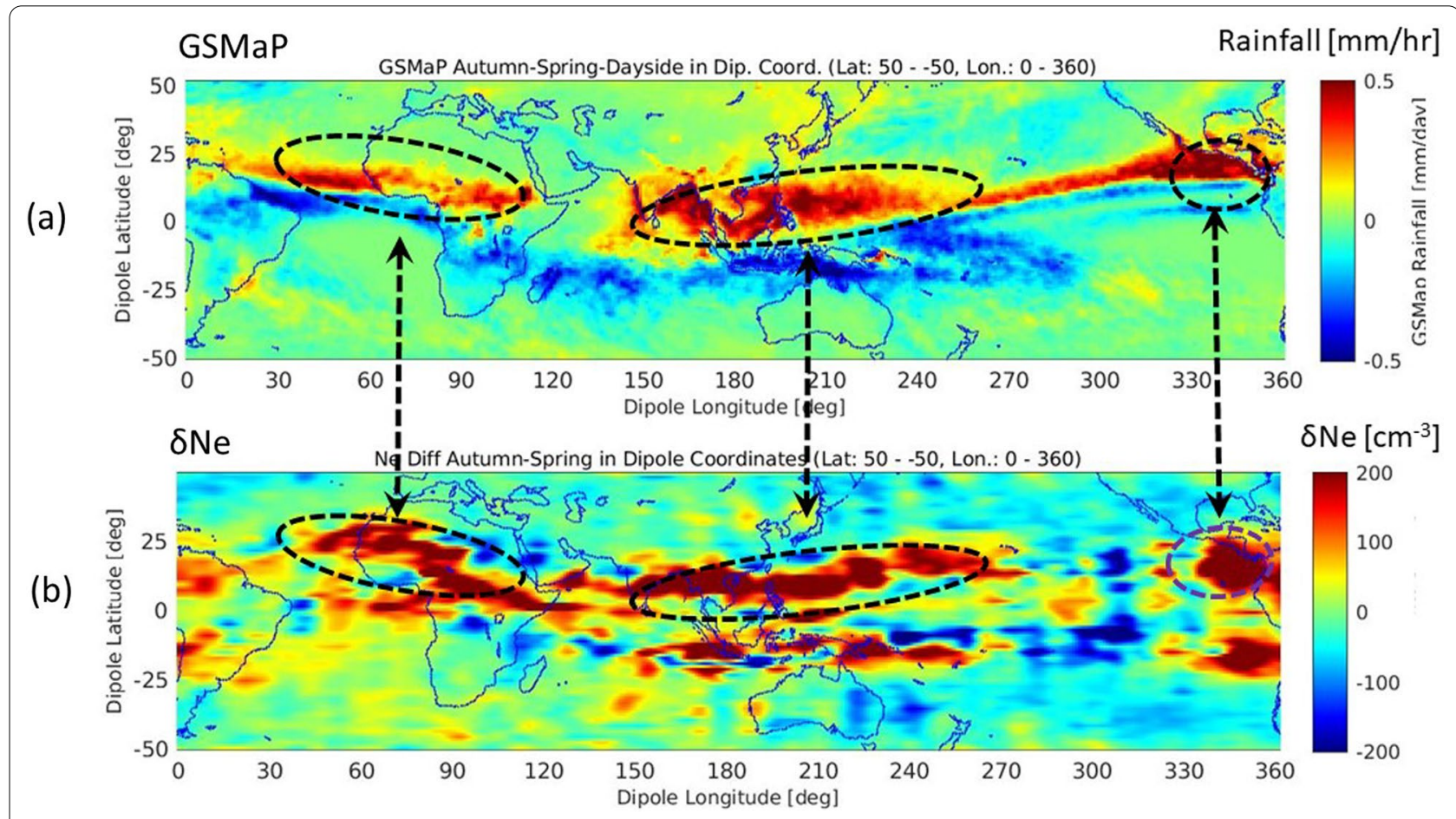

Fig. 5 a Difference of mean rainfall between autumnal equinox (Aug-Oct) and vernal equinox (Feb-Apr), b same as a but of mean electron density fluctuations

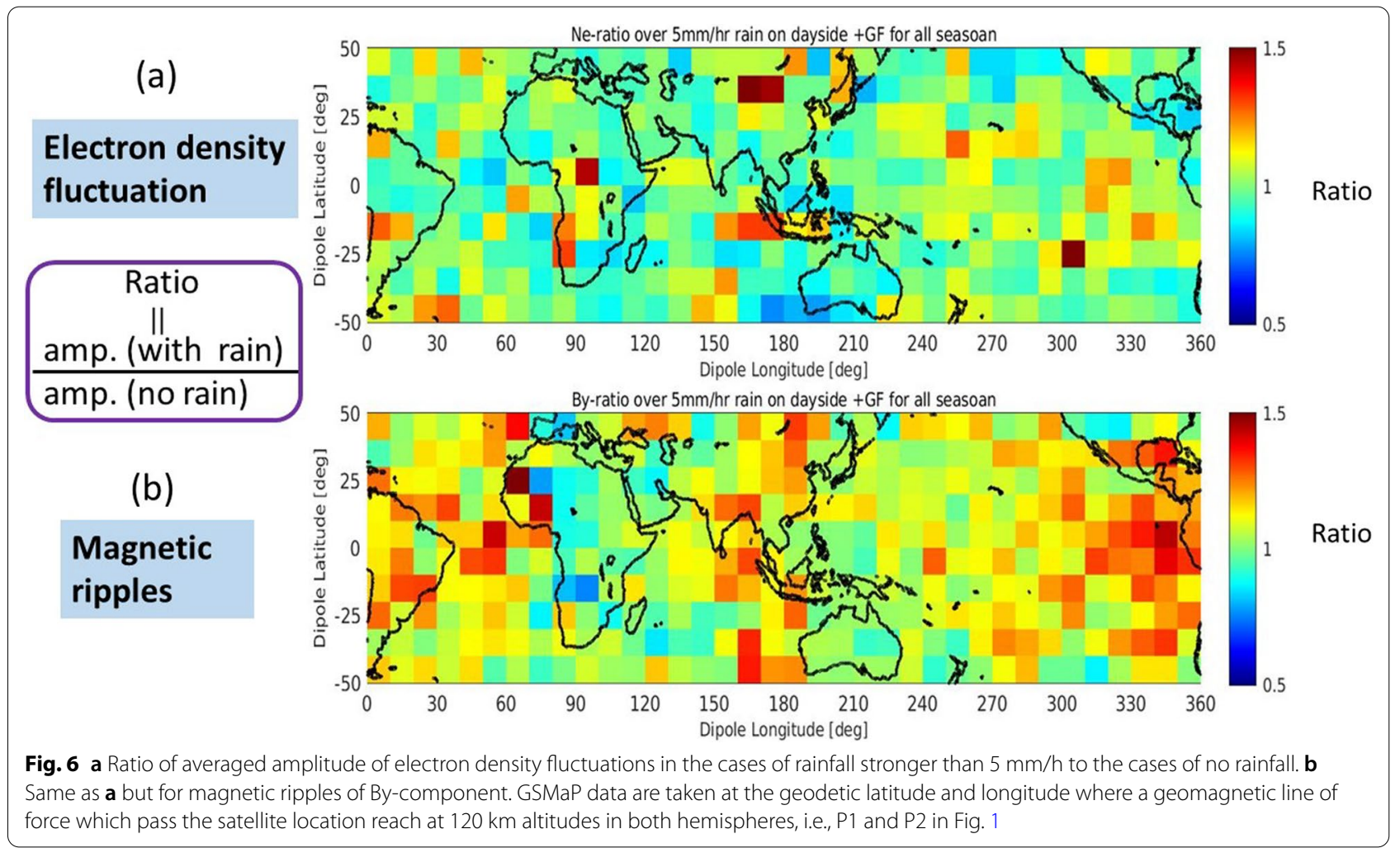




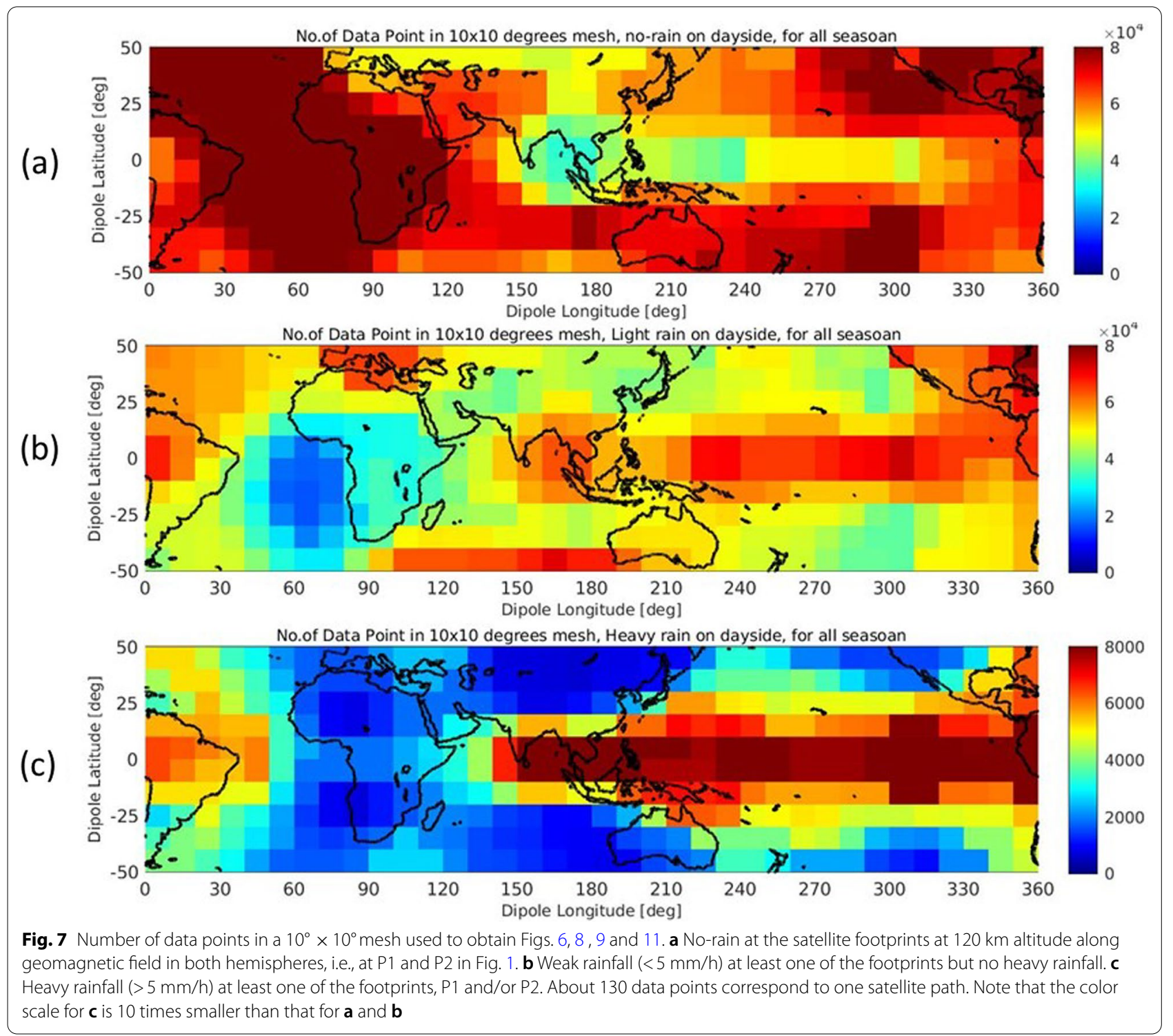

shows the case where at least one side of magnetic conjugate points, i.e., P1 or P2 in Fig. 1, have weak $(<5 \mathrm{~mm} / \mathrm{h})$ rainfall, and $\mathrm{c}$ is for heavy $(>5 \mathrm{~mm} / \mathrm{h})$ rainfall cases at $\mathrm{P} 1$ and/or P2. The $5 \mathrm{~mm} / \mathrm{h}$ threshold is adopted in this study because the minimum number of satellite path ('not' the number of data points) in every mesh is greater than around 10 with this threshold. Note that the tendency of north-south symmetry is caused by the adoption of magnetic conjugate points to check the rainfall condition.

Figure $8 \mathrm{a}$ and $\mathrm{b}$ correspond to Fig. $6 \mathrm{a}$ and $\mathrm{b}$, respectively, but in Apex coordinates, because the magnetic equator (i.e., the dip equator) differs about 15 degrees from dipole equator in some longitudinal area, in particular over the Atlantic Ocean and western Africa areas as seen in Fig. 3. Although the rough tendency is similar between Figs. 6 and 8, it may be more suitable to use Apex coordinates when we average in longitudinal direction and compare the values of the amplitude ratio because equatorial anomaly could play a significant role to generate the electron density fluctuations. Therefore, we use the Apex coordinates for Figs. 9, 10 and 11 where the longitudinal averages are examined. The blank area within around $\pm 10^{\circ}$ Apex latitudes appears because the geomagnetic lines of force in low-latitude do not reach the satellite orbit as explained with Fig. 1. Note that the Apex latitude of the coastlines depicted in Fig. 8 is 


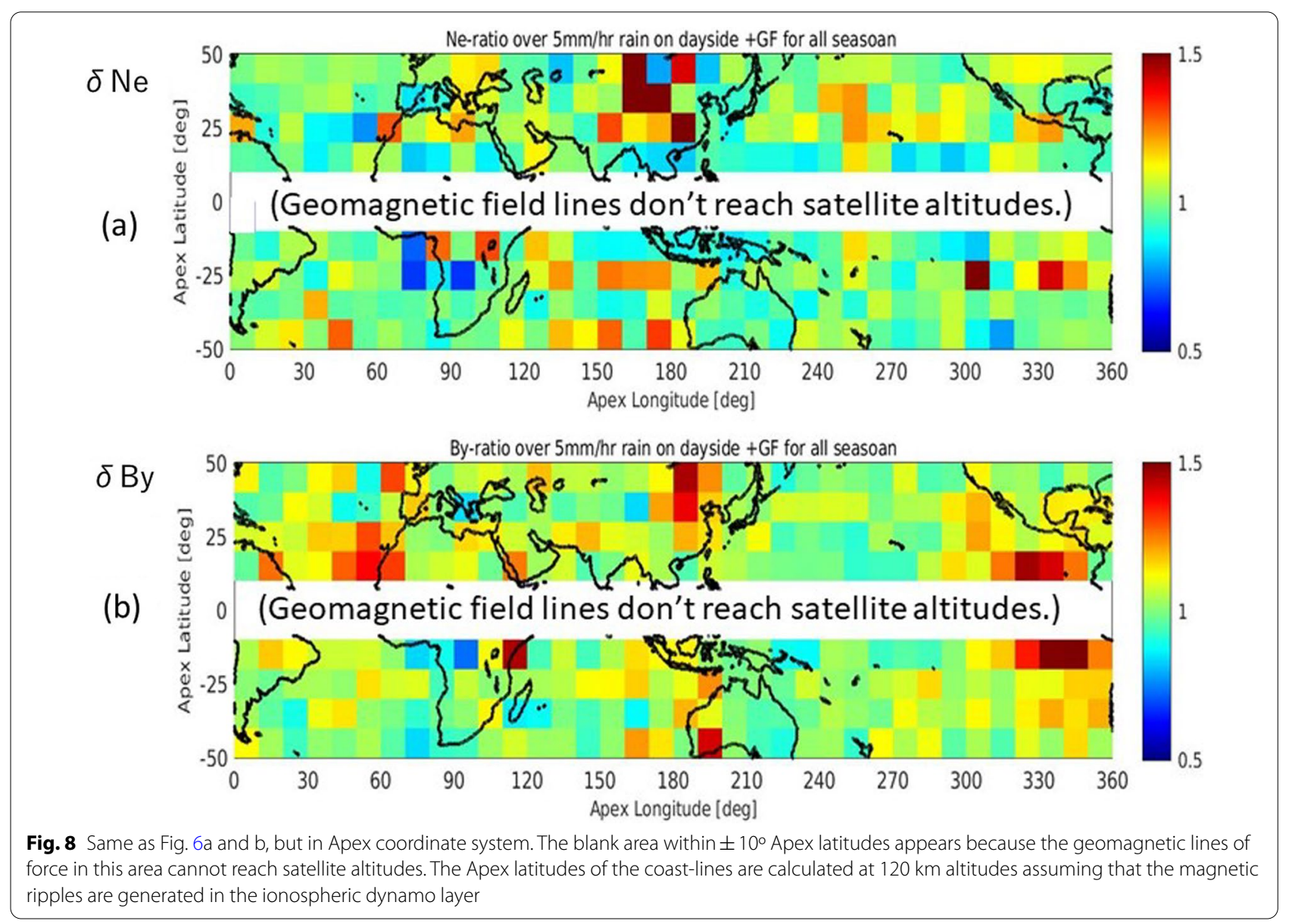

calculated at an altitude of $120 \mathrm{~km}$ assuming that the neutral atmospheric waves from lower atmosphere start to cause magnetic and electron density variations after they reach the lower ionosphere.

Figure 9a shows the plots of longitudinally averaged ratios of electron density fluctuations (blue line) corresponding to Fig. $8 \mathrm{a}$ and magnetic ripples in $\mathrm{Bx}$ - and Bycomponents (orange and black lines, respectively, and black line corresponds to Fig. 8b). The error bars indicate the standard error $(=\sigma / \sqrt{n})$ where $\sigma$ is the standard deviation at each Apex latitude and $n=36$, i.e., 36 meshes in longitudinal direction, in this case. Figure 9a is the case when the strength of rainfall is greater than $5 \mathrm{~mm} / \mathrm{h}$ at least one hemisphere and Fig. $9 \mathrm{~b}$ is for weak rainfall cases less than $5 \mathrm{~mm} / \mathrm{h}$. A comparison of Fig. $9 \mathrm{a}$ and $b$ shows the effect of rainfall strength on the amplitude ratio. The excess of the ratio from 1.0 for $\delta B x$ and $\delta$ By in heavy rain case is about 1.5-2 times of those in weak rainfall cases. It should be noted that the amplitude of electron density fluctuation, $\delta \mathrm{Ne}$, does not show any clear rainfall intensity dependence. This difference for $\delta \mathrm{Ne}$ with the results for $\delta \mathrm{Bx}$ or $\delta \mathrm{By}$ is probably caused by the use of field-line tracing to $120 \mathrm{~km}$ altitude to refer to the GSMaP data as shall be discussed later with.

Figure 10a and $\mathrm{b}$ respectively show the plots of longitudinally averaged ratios of electron density fluctuations and magnetic ripples for four seasons. The definition of four seasons in this paper is "ionospheric" season which is mainly controlled by the solar UV intensity (i.e., by the Solar zenith angle). On the other hand, the season on the ground shifts one or two months late from ionospheric seasons. The GSMaP data at the same geodetic latitude and longitude of satellite location, i.e., P0 in Fig. 1, are used. Although the ratios scatter by seasons, and the error bars are larger than those in Fig. 9 or in Fig. 11, it is still greater than 1.0 (horizontal red line) for most of the data points.

Figure 11a shows a result when a field-line tracing with IGRF2015 from a satellite location to altitude $120 \mathrm{~km}$ in both hemispheres is applied to find the location where 


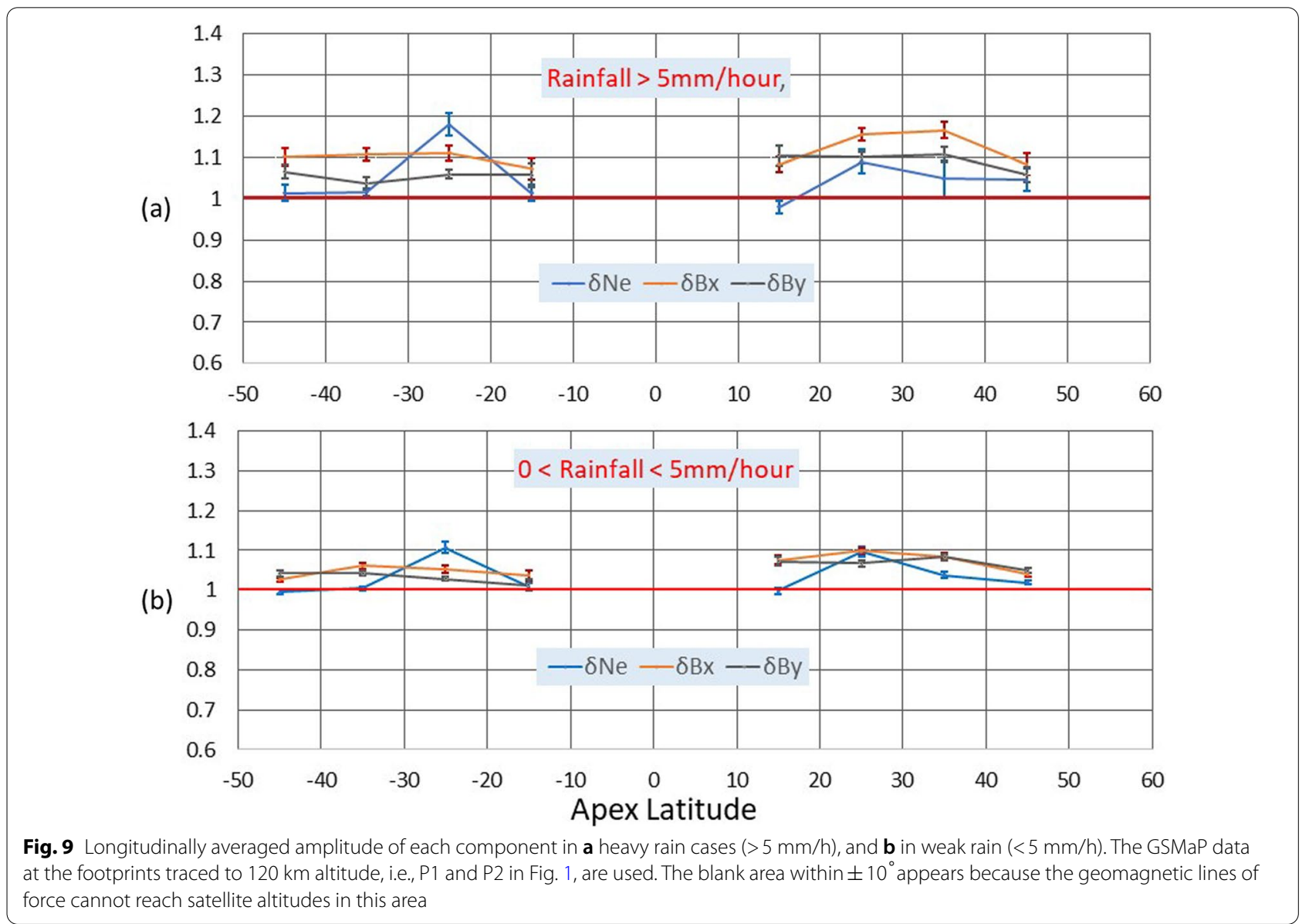

the GSMaP rainfall value is taken. That is, the GSMaP data at the geodetic latitude and longitude of P1 and P2 in Fig. 1 are referred to. Figure 11b shows a result when geodetic latitude and longitude at the satellite, i.e., P0 in Fig. 1, are used to pick-up the GSMaP data, i.e., the rainfall vertically below the satellite. For magnetic ripples, i.e., for $\delta \mathrm{Bx}$ and $\delta \mathrm{By}$, the ratio is larger in low latitudes in the case of tracing, i.e., Fig. 11a, than the case of no-tracing, i.e., Fig. 11b. Because the latitudinal difference between Apex and dipole coordinates of a given point is larger in lower latitudes, this result is consistent with the interpretation that the magnetic ripples are small-scale fieldaligned current structure which is generated in lower ionosphere by a dynamo process. However, the ratio for electron density fluctuation, $\delta \mathrm{Ne}$, tends to be larger in the case of no tracing (Fig. 11b) than that of tracing (Fig. 11a). This suggests that the mechanism which generates $\delta \mathrm{Ne}$ is different from that of the magnetic ripples as has been expected from Fig. 2. The electron density fluctuations, $\delta \mathrm{Ne}$, seem to be generated more directly by an atmospheric wave propagated vertically upward to the satellite altitude.
Figure $11 \mathrm{~b}$ and $\mathrm{c}$ are respectively the cases of heavy rainfall $(>5 \mathrm{~mm} / \mathrm{h})$ and of weak rainfall $(0<$ rainfall $<5 \mathrm{~mm} / \mathrm{h}$ ) vertically below the satellite, i.e., without geomagnetic field-line tracing to $120 \mathrm{~km}$ altitude. A comparison of the ratios for $\delta \mathrm{Ne}$ in Fig. $11 \mathrm{~b}$ and c support the above suggestion because the ratios of $\delta \mathrm{Ne}$ are larger for heavy rainfall cases than the cases of weak rainfall cases when we use the GSMaP data directly under the satellite location. The location of magnetic ripples appears more equatorward than the location of electron density fluctuations in Fig. 2. This latitudinal shift is also consistent with the idea of vertically upward propagation of the waves to the Swarm satellite altitude and the generation of the electron density fluctuations there.

\section{Conclusion}

The global distribution and its seasonal variation of magnetic ripples and electron density fluctuations on the dayside have similarities with distribution of rainfall estimated by the GSMaP as seen in Figs. 3, 4, and 5 . These similarities suggest a connection between lower atmospheric disturbance indicated by rainfall as a proxy 


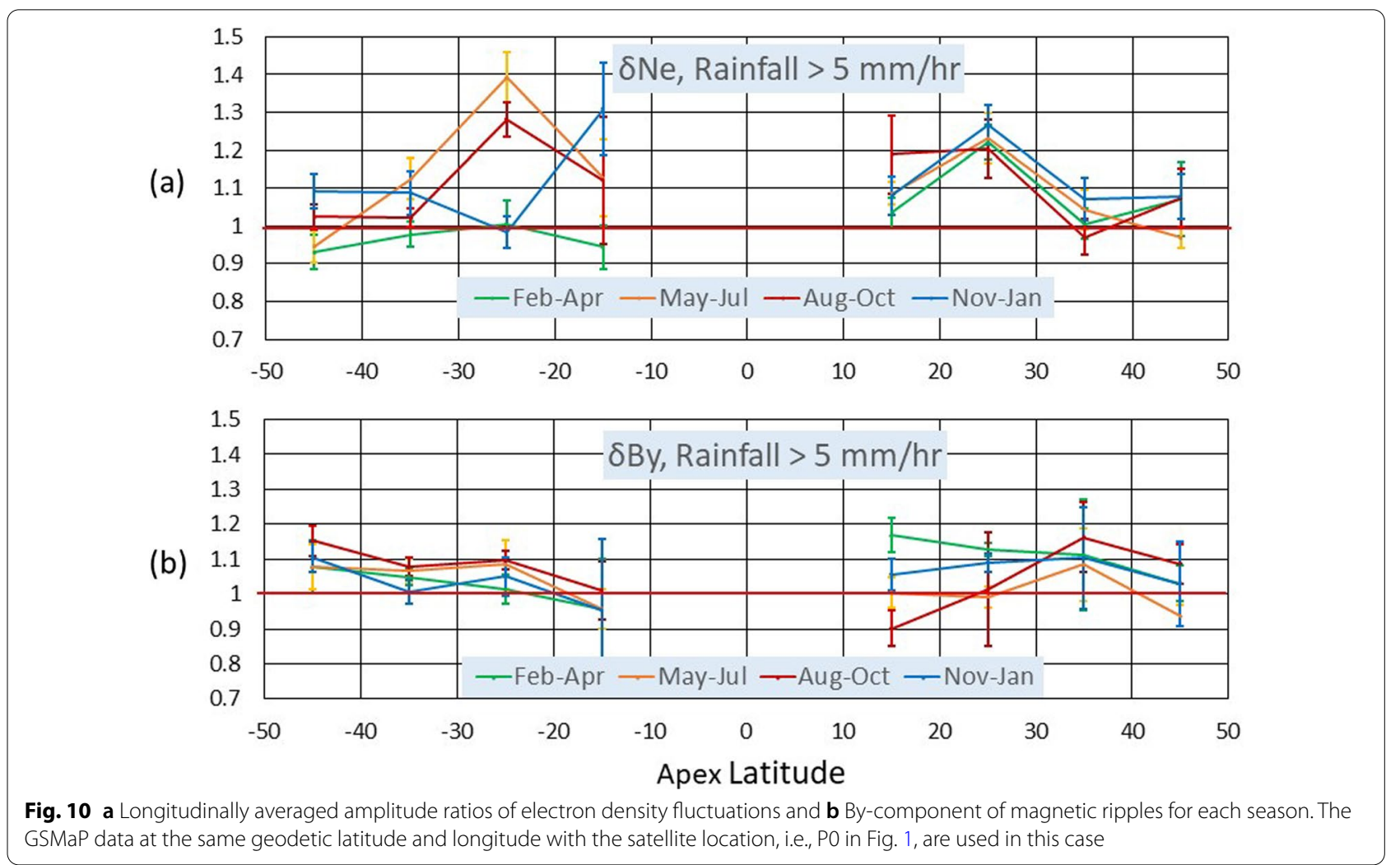

of atmospheric disturbance and ionospheric disturbance. However, such similarities do not necessarily mean their causal relationship.

We calculated the ratio of their magnitude, i.e., amplitude of magnetic ripples or electron density fluctuations in rainfall cases to those in no-rainfall cases. Although the longitudinally averaged ratio is not very large but around 1.1-1.2 in $\pm 10^{\circ}- \pm 50^{\circ}$ Apex latitudes, it is clearly larger than 1.0. The ratio increases when the intensity of rainfall $(\mathrm{mm} / \mathrm{h})$ increases as shown in Fig. 9 and Fig. 11. These facts indicate the existence of some physical sequence for the generation of magnetic ripples and electron density fluctuations where the rainfall process is included. The source of the lower atmospheric waves could be a cumulous convection (Aoyama et al. 2017) and/or a pressure variation which is driven by falling raindrops (or ice grain) above a strong rainfall region. That is, a pressure decrease above strong rainfall could cause a rarefaction wave which propagates upward as an acoustic wave.

As for the mode of atmospheric waves, i.e., acoustic wave or internal gravity wave, acoustic mode has been suggested as the main driver of magnetic ripples (e.g., Iyemori et al. 2015). The results of larger amplitude ratio for magnetic ripples when we use the rainfall location traced along geomagnetic field line from satellite location to an altitude, $120 \mathrm{~km}$, than no-tracing (Fig. $11 \mathrm{a}$ and b) support the idea of acoustic mode because an acoustic wave can propagate vertically upward but an internal gravity wave can propagate upward only with some inclined angle and tends to spread horizontally making the spatial correlation weaker. About $90 \mathrm{~min}$ or more is necessary for internal gravity waves to travel to the satellite altitude around $500 \mathrm{~km}$. This could also make the correlation with satellite observation weaker. On the other hand, the acoustic wave can propagate vertically upward and reach satellite altitude within about $20 \mathrm{~min}$. Therefore, the acoustic waves have more chance to show the correlation between rainfall and satellite observation above the rainfall area. On the possible time delay between a rainfall and appearance of its effect in the ionosphere, we checked it by shifting the time (hours) from zero to three hours. Although not shown in this paper, the result showed that no time shift case gave the highest ratio in most latitudes although the difference is not very large. Therefore, we didn't shift the time between the GSMaP and the Swarm observation. 


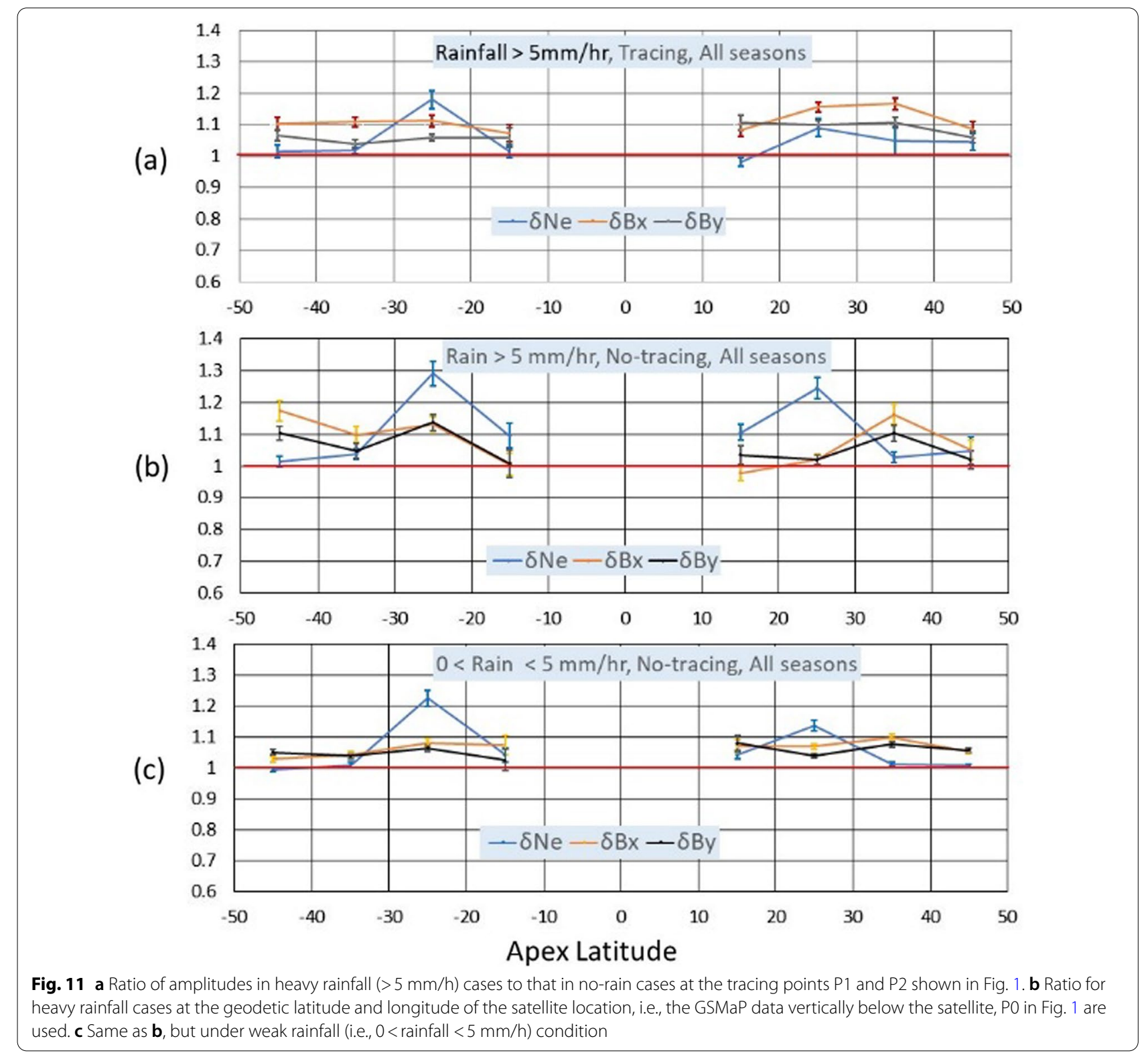

As for the electron density fluctuations, the ratio is larger for no-tracing case in lower latitude (Fig. 11a and b). The ratio is larger for heavy rain case as seen from Fig. 11b and c. These facts and the latitudinal shift between magnetic ripples and electron density fluctuations shown in Fig. 2 suggest that the electron density fluctuations are more directly generated by the waves propagated vertically upward to the satellite location from lower atmospheric source region. This support the idea that the acoustic mode waves are the cause of the electron density fluctuations. Although such cases having correspondence with latitudinal shift are frequently observed, there also exist more cases without the correspondence. Therefore, to make this point clear, more event study on the latitudinal shift between magnetic ripples and electron density fluctuations is necessary. 


\section{Appendix}

Non-natural variation in the Langmuir probe electron density data: A systematic variation apparently not natural phenomenon typically shown in Fig. 12 often appears in the electron data set used in this paper. Fig. 13 shows the period and local time plot where such non-natural variations are detected by eye-inspection. We excluded the days when the non-natural variations were detected in the dataset that covers $\pm 50^{\circ}$ dipole latitudes.

Their characteristics are as follow:

1. It starts to appear with small amplitude and narrow latitudinal width at almost the same geodetic latitude on a daily plot like Fig. 12.
2. It appears in the data from both Swarm-A and -C. However, it appears with a few days delay. It appears also in the data from Swarm-B, however, the period is different from that of Swarm-A and -C.

3. During a day, the variations appear approximately at the same geographic (geodetic) latitudes as seen in Fig. 12. Similar variations appear in the data from the SW-C (right panel), 2 days later than the date for SW-A (left panel). These variations appear for several days or for a few weeks changing the latitude, amplitude and latitudinal pattern.

4. They tend to appear in pre-noon, afternoon, after sunset and before dawn (Fig. 13).

5. About $1 / 3$ of the orbit in middle and low latitudes contain such non-natural variations. That is, 71,933 half-orbits in total 204,395 half-orbits include such non-natural $\delta \mathrm{Ne}$ variations (Fig. 13).

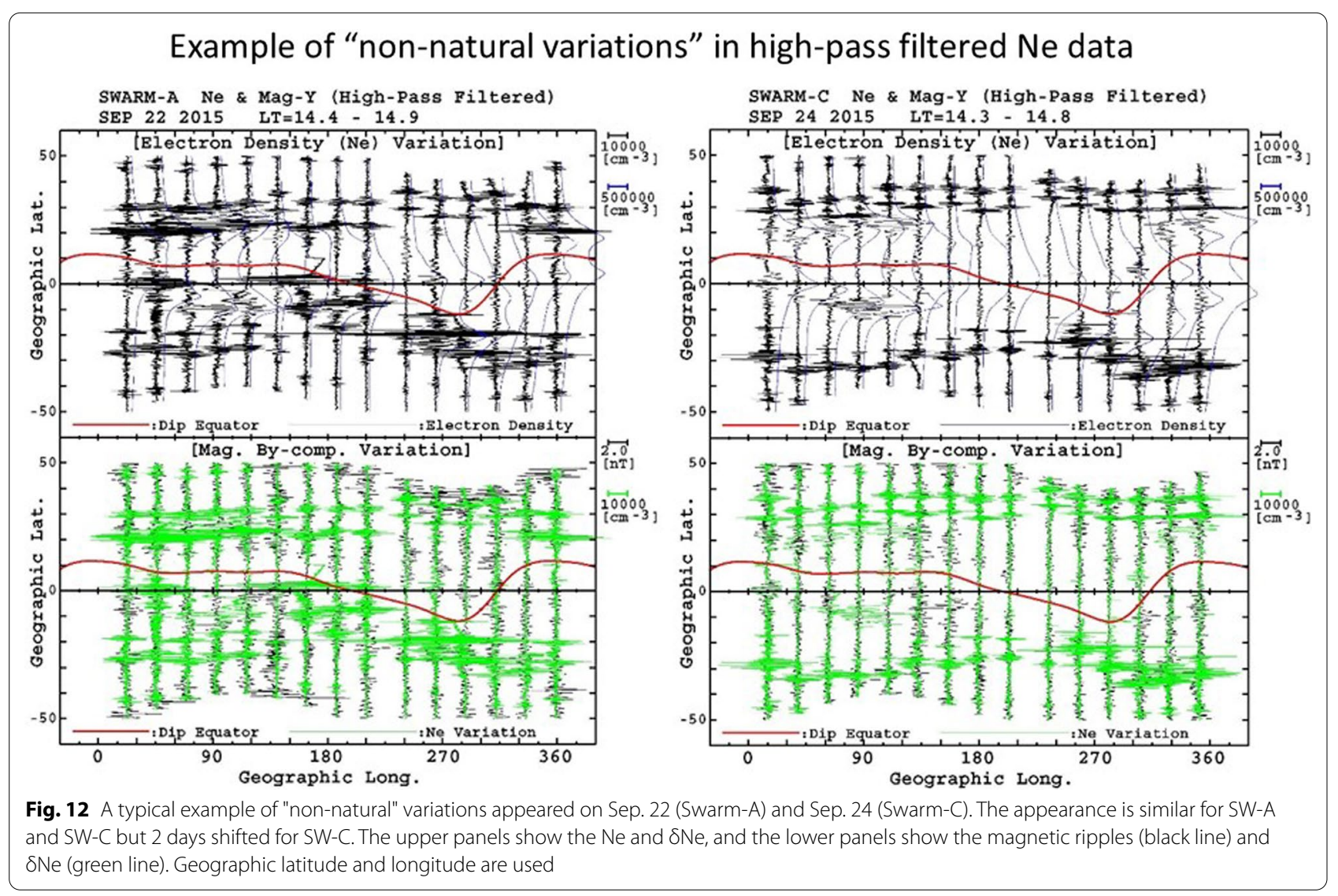




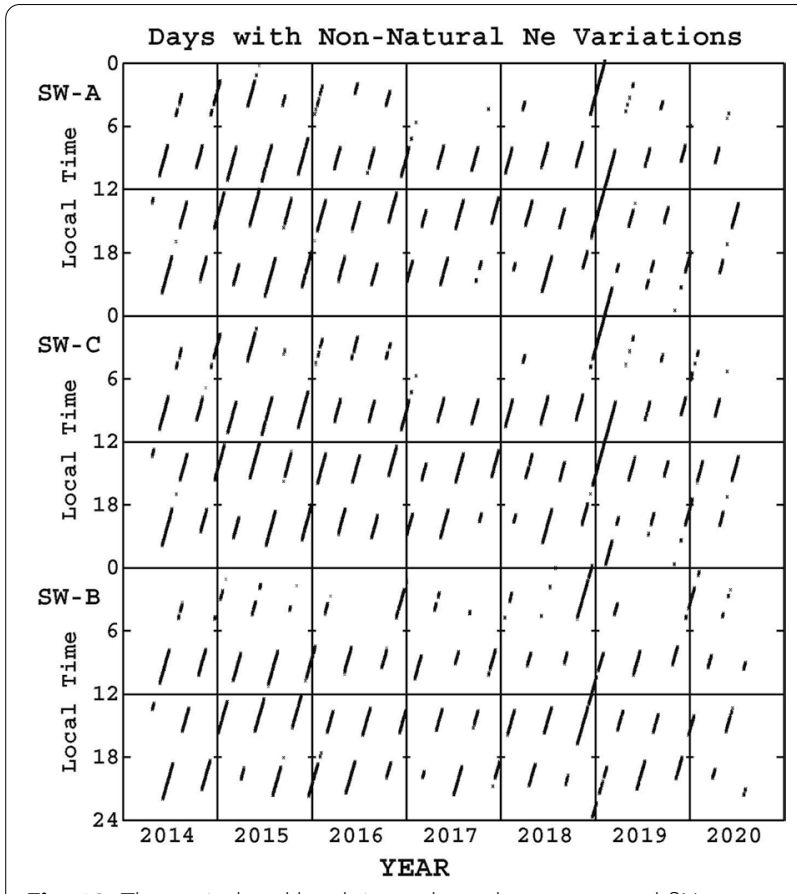

Fig. 13 The period and local time where the non-natural $\delta \mathrm{Ne}$ variations appear. All the data from March 2014 to July 2020 were eye-inspected using the plots similar to Fig. 12 to detect 'non-natural' variations

\begin{abstract}
Abbreviations
CHAMP: Challenging Minisatellite Payload; ESA: European Space Agency; GSMaP: Global Satellite Mapping of Precipitation; IAGA: International Association of Geomagnetism and Aeronomy; IGRF: International Geomagnetic Reference Field; JAXA: Japan Aerospace Exploration Agency; JSPS: Japan Society for the Promotion of Science; LP: Langmuir probe; MEF: Mid-latitude ionospheric Electric field Fluctuations; MMF: Mid-latitude ionospheric Magnetic field Fluctuations; SW-A: Swarm-A; VFM: Vector Field Magnetometer.
\end{abstract}

\section{Acknowledgements}

Swarm data are provided by a research proposal (ID: 10230) to the Swarm Science and Validation Opportunity Project under the ESA. The GSMaP data are provided by JAXA GSMaP project. This study has been supported by the JSPS grants $15 \mathrm{H} 05815,17 \mathrm{~K} 05669,20 \mathrm{H} 00099$ and $21 \mathrm{~K} 03643$. The authors thank the World Data Center for Geomagnetism, Kyoto for keeping the Swarm Satellite Data downloaded from the ESA during the period of this analysis.

\section{Authors' contributions}

TI performed data analysis and prepared the draft text and figures, and TA and YY checked them: TA downloaded the Langmuir Probe data from ESA data repository and converted them for analysis: YY downloaded the VFM data and high-pass filtered them for analysis. TI, TA and YY discussed the results of analysis based on their previous Swarm data analysis. All authors read and approved the final manuscript.

\section{Funding}

This study has been supported by the JSPS grants (Kakenhi) 15H05815, 17K05669, $20 \mathrm{H} 00099$ and 21K03643.

\section{Availability of data and materials}

Swarm VFM and LP data are downloadable from https://swarm-diss.eo.esa. int/. Information on the GSMaP data and their use are obtained from https:// sharaku.eorc.jaxa.jp/GSMaP/guide.html. Registration is requested to download by ftp.

\section{Declarations}

Ethics approval and consent to participate

Not applicable.

\section{Consent for publication}

Not applicable.

\section{Competing interests}

The authors declare that they have no competing interests.

\section{Author details}

${ }^{1}$ Graduate School of Science, Kyoto University, Kyoto 606-8502, Japan.

${ }^{2}$ F-Factory Co., Ltd, Kasugaoka 1-129, Nabari 518-0453, Japan. ${ }^{3}$ Swedish Institute of Space Physics, Box 812, 98128 Kiruna, Sweden.

Received: 29 September 2021 Accepted: 21 February 2022

Published online: 02 March 2022

\section{References}

Aoyama T, Iyemori T, Nakanishi K, Nishioka M, Rosales D, Veliz O, Safor EV (2016) Localized field-aligned currents and 4-min TEC and ground magnetic oscillations during the 2015 eruption of Chile's Calbuco volcano. Earth Planets Space 68(1):148. https://doi.org/10.1186/s40623-016-0523-0

Aoyama T, Iyemori T, Nakanishi K (2017) Magnetic ripples observed by Swarm satellites and their enhancement during typhoon activity. Earth Planets Space 69:89. https://doi.org/10.1186/s40623-017-0679-2

Calais E, Minster JB (1995) GPS detection of ionospheric perturbations following the January 17, 1994, Northridge earthquake. Geophys Res Lett 22:10451048. https://doi.org/10.1029/95GL00168

Choosakul N, Saito A, lyemori T, Hashizume M (2009) Excitation of 4-min periodic ionospheric variations following the great Sumatra-Andaman earthquake in 2004. J Geophys Res 114:A10313. https://doi.org/10.1029/2008JA013915

Heki K (2006) Explosion energy of the 2004 eruption of the Asama Volcano, central Japan, inferred from ionospheric disturbances. Geophys Res Lett 33:L14303. https://doi.org/10.1029/2006GL026249

Heki K, Ping J (2005) Directivity and apparent velocity of coseismic ionospheric disturbances observed with a dense GPS array. Earth Planet Sci Lett 236:845-855. https://doi.org/10.1016/j.epsl.2005.06.010

lyemori T, Nakanishi K, Aoyama T, Yokoyama Y, Koyama Y, Lühr H (2015) Confirmation of existence of the small-scale field-aligned currents in middle and low latitudes and an estimate of time scale of their temporal variation. Geophys Res Lett. https://doi.org/10.1002/2014GL062555

Kanamori H, Mori J, Harkrider DG (1994) Excitation of atmospheric oscillations by volcanic eruptions. J Geophys Res 99:21947-21961. https://doi.org/10.1029/ 94JB01475

Knudsen DJ, Burchill JK, Buchert SC, Eriksson Al, Gill R, Wahlund J-E, Åhlen L, Smith M, Moffat B (2017) Thermal ion imagers and Langmuir probes in the Swarm electric field instruments. J Geophys Res Space Physics 122:2655-2673. https://doi.org/10.1002/2016JA022571

Martines-Bedenko VA, Pilipenko VA, Zakharov VI, Grushin VA (2019) Influence of the Vongfong 2014 hurricane on the ionosphere and geomagnetic field as detected by SWARM satellites: 2 geomagnetic disturbances. Sol Terr Phys 5(4):74-80. https://doi.org/10.12737/stp-54201910

Merayo, J. M. G. (2014), The Swarm Vector Field Magnetometer (VFM): instrument commissioning \& performance assessment,3rd Swarm Science Meeting, https://earth.esa.int/documents/1578837/1578843/0B_Merayo_Swarm_ VFM.pdf/510c969b-4baf-42b9-a038-fea863ca07a5;jsessionid=3B9A8BABFF F15DD955B35AF7816D0A6A.jvm1?version $=1.0$

Nakanishi K, lyemori T, Taira K, Lühr H (2014) Global and frequent appearance of small spatial scale field aligned currents possibly driven by the lower atmospheric phenomena as observed by the CHAMP satellite in middle and low latitudes. Earth Planets Space 66:40. https://doi.org/10.1186/ 1880-5981-66-40

Nishioka M, Tsugawa T, Kubota M, Ishii M (2013) Concentric waves and shortperiod oscillations observed in the ionosphere after the 2013 Moore EF5 tornado. Geophy Res Lett. https://doi.org/10.1002/2013GL057963 
Olsen N, Friis-christensen E, Floberghagen R et al (2013) The Swarm satellite constellation application and research facility (SCARF) and Swarm data products. Earth Planets Space 65:1189-1200. https://doi.org/10.5047/eps. 2013.07.001

Park J, Lühr H, Stolle C et al (2009) The characteristics of field-aligned currents associated with equatorial plasma bubbles as observed by the CHAMP satellite. Ann Geophys 27:2685-2697. https://doi.org/10.5194/ angeo-27-2685-2009

Park J, Lühr H, Stolle C, Rodriguez-Zuluaga JS, Knudsen DJ, Burchill JK, Kwak Y-S (2016) Statistical survey of nighttime midlatitude magnetic fluctuations: their source location and Poynting flux as derived from the Swarm constellation. J Res Geophys. https://doi.org/10.1002/2016JA023408

Perkins F (1973) Spread F and ionospheric currents. J Geophys Res 78:218-226

Perwitasari S, Sakanoi T, Yamazaki A, Otsuka Y, Hozumi Y, Akiya Y, Saito A, Shiokawa K, Kawamura S (2015) Coordinated airglow observations between IMAP/ VISI and a ground-based all-sky imager on concentric gravity wave in the mesopause. J Geophys Res 120:9706-9721. https://doi.org/10.1002/2015 J A021424

Richmond AD (1995) lonospheric electrodynamics using magnetic apex coordinates. J Geomag Geoelectr. https://doi.org/10.5636/jgg.47.191

Saito A, lyemori T, Sugiura M et al (1995) Conjugate occurrence of the electric field fluctuations in the nighttime midlatitude ionosphere. J Geophys Res 100:21439-21451

Saito A, Tsugawa T, Otsuka Y, Nishioka M, Iyemori T, Matsumura M, Saito S, Chen CH, Goi Y, Choosakul N (2011) Acoustic resonance and plasma depletion detected by GPS total electron content observation after the 2011 Tohoku Earthquake. Earth Planets Space 63:863-867. https://doi.org/10.5047/eps. 2011.06 .034

Shao X-M, Lay EH (2016) The origin of infrasonic ionosphere oscillations over tropospheric thunderstorms. J Geophys Res Space Physics 121:6783-6798. https://doi.org/10.1002/2015JA022118

Shinagawa H, lyemori T, Saito S, Maruyama T (2007) A numerical simulation of ionospheric and atmospheric variations associated with the Sumatora earthquake on December 26, 2004. Earth Planets Space 59:1015-1026

Stolle C, Lühr H, Rother M, Balasis G (2006) Magnetic signatures of equatorial spread F as observed by the CHAMP satellite. J Geophys Res 111:A02304. https://doi.org/10.1029/2005JA011184

VanZandt TE, ClarkWL, Warnock JM (1972) Magnetic apex coordinates: a magnetic coordinate system for the ionospheric $\mathrm{F} 2$ layer. J Geophys Res 77:2406-2411. https://doi.org/10.1029/JA077i013p02406

Zettergren MD, Snively JB (2015) lonospheric response to infrasonic-acoustic waves generated by natural hazard events. J Geophys Res Space Phys 120:8002-8024. https://doi.org/10.1002/2015JA021116

Zettergren MD, Snively JB (2019) Latitude and longitude dependence of ionospheric TEC and magnetic perturbations from infrasonic-acoustic waves generated by strong seismic events. Geophys Res Lett 46:1132-1140. https://doi.org/10.1029/2018GL081569

\section{Publisher's Note}

Springer Nature remains neutral with regard to jurisdictional claims in published maps and institutional affiliations.

\section{Submit your manuscript to a SpringerOpen ${ }^{\circ}$ journal and benefit from:}

- Convenient online submission

- Rigorous peer review

- Open access: articles freely available online

- High visibility within the field

- Retaining the copyright to your article

Submit your next manuscript at $\boldsymbol{\nabla}$ springeropen.com 